\title{
Shift changes in various pulmonary function parameters in ginning mill workers
}

\author{
Dr Sujatha Talikoti. ${ }^{1}$,Dr Anand.N. Patil. ${ }^{2}$, Dr Manjunatha.Aithala. ${ }^{3}$, Dr Sumangla .M. \\ Patil. $^{4}$ \\ ${ }^{1}$ Assistant professor Department of physiology BLDE University Sri B M Patil Medical College and Research Center \\ BIJAPUR-586103; KARNATAKA. \\ ${ }^{2}$ Associate professor Department of Medicine Al-Ameen Medical College .BIJAPUR -586103 .KARNATAKA. \\ ${ }^{3}$ Professor and HOD . Department of physiology BLDE University Sri BM Patil Medical College and Research Center \\ ,BIJAPUR-586103. KARNATAKA. \\ ${ }^{4}$ Professor Department of Physiology Sri B M Patil Medical College and Research Center. BIJAPUR-586103. \\ KARNATAKA.
}

\begin{abstract}
Background

In Northern part of Karnataka there are many ginning factories associated with processing with processing of cotton. However there is no evaluation of pulmonary function status of the workers working with these mills.

Objectives

The present study therefore was planned to measure the over shift changes in lung functions in workers of $g$ inning factory of Bijapur District.

Materials and Methods

The study was conducted on 67 subjects who were workers of aginning factory in Bijapur. Tests were carried out on Monday. This was done to evaluate the problem on first day of week after a week end break as suggested in various other studies. The questionnaires interview was conducted early in the morning on Monday before starting of the shift. The pulmonary function tests [FVC, FEV1, FEV1\% and PEFR] were performed twice on the same day [8am-10am after 5pm] to assess the over shift change in pulmonary function

Results

Over shift changes in FVC, FEV1,FEV1 \%and PEFR, There is a over shift decrease of $7.19 \%$ in FVC, $11.34 \%$ decrease in FEV1,4.68\% decrease in FEV1\% and 10.73\% decrease PEFR.

Conclusion

There was a significant change in values of pulmonary function parameters recorded at the end of shift from the values recorded at the beginning of the shift.

Keywords - Pulmonary function tests, over shift,

INTRODUCTION-

The fact that exposure to organic dust including cotton dust has deleterious effect on human being is recognized since the start of farming.

In Northern part of Karnataka there are many ginning factories associated with processing of cotton. However there is no evaluation of shift changes in pulmonary function status of the workers in these mills.
\end{abstract}

\section{AIMS AND OBJECTIVES -}

To assess the shift changes in pulmonary function status of the workers of ginning factory of Bijapur, District[North Karnataka].

\section{MATERIALS AND METHODS-}

The present study was planned to measure the shift changes in lung functions in workers of a ginning factory of Bijapur District North Karnataka. The study was conducted on 67 subjects who were workers of ginning factory in Bijapur.

Tests were carried out on the subjects on every Monday of the week. This was done to evaluate the problem on first day of week after a week end break as suggested in various other studies. 1

The questionnaire interview was conducted early in the morning on Monday before starting of the shift to subjects. 
The pulmonary function tests [FEV, FEV1, FEV1\%, \&PEFR] were performed twice on the same day [8-10am \& after $5 \mathrm{pm}]$ to assess the shift changes in pulmonary function on them.

\section{STATISTICAL ANALYSIS}

All the values are expressed in mean + SEM including SD. The level of significance is calculated by applying ' $Z$ ' test and ' $\mathrm{P}$ ' values at 5\% level are considered as significant.

Analysis variance [ANOVA] test was applied to compare the mean values of various groups.

Table represents shift changes in various Pulmonary function parameters. [Values are in Mean \pm SD ]

\begin{tabular}{|l|l|l|l|}
\hline Parameters & Before shift & After shift & Difference \\
\hline FVC $[\mathrm{ml}]$ & $\mathbf{2 2 0 9 . 8 8} \pm \mathbf{6 3 9 . 2 9 2}$ & $\mathbf{2 0 5 0} \pm \mathbf{5 4 0 . 8 3}$ & $\mathbf{1 5 9 . 0 [ 7 . 1 9 \%}]$ \\
\hline FEV1 [ml] & $\mathbf{1 7 7 3 . 8 8} \pm 673.508$ & $1572.1 \pm 562.13$ & $\mathbf{2 0 1 . 1 6}[11.34 \%]$ \\
\hline FEV1\% & $\mathbf{7 9 . 6 0 \pm 0 . 1 4 5}$ & $\mathbf{7 5 . 9} \pm \mathbf{0 . 1 1 8}$ & $\mathbf{3 - 7}[4.68 \%]$ \\
\hline PEFR $[$ lit/min] & $\mathbf{3 3 1 . 3 9 5} \pm 40.4448$ & $\mathbf{2 9 5 . 8 1} \pm 41.07$ & $\mathbf{3 5 . 5 8}[10.73 \%]$ \\
& & & \\
\hline
\end{tabular}

There is significant decrease of $7.19 \%$ in FVC, $11.34 \%$ decrease in FEV1, $4.68 \%$ decrease in FEV1\% and $10.73 \%$ decrease in PEFR in shift workers.

\section{DISCUSSION}

In our study we have observed a decline in all the respiratory parameters at the end of the shift in comparison to that recorded at the beginning of the shift.

Bouhuys et. al. G. B. Field and P .Owen and K.Y Mustafa et ,al in their study reported significant shift fall in FVC and FEV1.,

Gandevia et.al reported that there is a decline in FEV1 in workers at the begging of the week and that continues throughout the week. Kama t, SR, reported a very large decline of FEV1 in cotton workers .,5

There was a significant change in values of pulmonary function parameters recorded at the end of shift from the values recorded at the beginning of the shift

\section{CONCLUSION}

Thus measurement of pulmonary function parameters before \& after shift is one of the most important tools that offer the opportunity of prospectively selecting workers at risk through pre employment examinations and periodic follow up.

\section{BIBLIOGRAPHY}

1. FIELD G.B.\& OWEN P.[1979]Respiratory function in Australian cotton mill Bull. "Europ. Physiopath resp". 15,455-468.

2. BOUHUYS A[1971]; Byssinosis Arch envir hlth;23:405-407

3. MUSTAFA K.Y. et.al. 1978 "Byssinosis, respiratory symptoms and spirometric lung function tests in Tanzanian sisal workers' 'Br J Ind Med;35:123-128.

4. GANDEVIA B,MILNNE J.:1965 "Ventilatory capacity changes on exposure to cotton dust and their relevance to byssinosis in Australia".Br J Ind med;22:295-304

5. KAMAT SR,KAMATGR,SALPEKAR VY,LOBO E.1981 “ Distinguishing byssinosis from chronic obstructive pulmonary disease“" Am Rev Respir Dis;124:31-41 